\title{
MECHANICAL PROPERTIES OF STEEL-POLYPROPYLENE HYBRID FIBER REINFORCED CONCRETE IN BUILDING STRUCTURE
}

\author{
Tao Zhang ${ }^{1}$ and Deng Pan²
}

\begin{abstract}
1. Architectural Engineering Department, Henan College of Transportation, Zhengzhou, Henan 450000, China; taodu9527@126.com

2. Highway College, Henan College of Transportation, Zhengzhou, Henan 450000, China
\end{abstract}

\begin{abstract}
This study mainly analyzed the effect of steel fiber (SF) mixed with polypropylene fiber (PF) on the performance optimization of concrete. Firstly, the steel fiber reinforced concrete (SFRC), polypropylene fiber reinforced concrete (PFRC) and steel-polypropylene hybrid fiber reinforced concrete (SP-HFRC) specimens were designed. Then, the slump experiment, compressive strength experiment, and tensile strength experiment were carried out. The results demonstrated that the increase of fibers reduced the slump, and the influence of PF on the slump was the largest, followed by SF and SP; when the content of SF was $1 \%$ and the content of PF was $0.1 \%$, the compressive strength and tensile strength of the concrete were $73.16 \mathrm{MPa}$ and $6.33 \mathrm{MPa}$, which was superior to the concrete mixed with single fiber. In the perspective of the seismic performance, the ultimate load of the SP-HFRC specimen was $6.25 \%$ higher than that of the plain concrete (PC) specimen, and its energy consumption was $126 \%$ higher than the PC specimen. The experimental results demonstrate that SP-HFRC has a superiority in mechanical property and can be further promoted and applied in building structure.
\end{abstract}

\section{KEYWORDS}

Hybrid fiber reinforced concrete, Steel fiber, Polypropylene fiber, Mechanical property

\section{INTRODUCTION}

As a kind of building material, concrete has been widely used in buildings, bridges, roads and tunnels because of advantages such as low price, convenient construction and good durability. But concrete also has some defects, such as low tensile strength, poor ductility and multiple cracks [1]. The existence of cracks will accelerate steel corrosion and affect the mechanical properties of the structure. With the development of society, the performance of ordinary concrete has not been able to meet people's needs. How to improve the performance of concrete has attracted more and more attention of researchers. It has been found that the addition of fibers in concrete is beneficial to reduce the occurrence of cracks and improve the tensile and crack resistance of concrete [2], while the performance optimization effect of two or more fibers is better than that of single fiber. Yang et al. [3] studied hooked steel fibers with various aspect ratios and volume fractions and found that the aspect ratio of the fibers increased from 65 to 80 and the reduction of $0.25 \%$ of the volume fraction of the fibers would not affect the optimization effect. Sadiqul Islam et al. [4] studied polypropylene fibers in different proportions $(0.10 \%, 0.15 \%, 0.2 \%, 0.25 \%$ and $0.3 \%)$ and found that the plastic 
shrinkage cracks of concrete which was added with fibers decreased by $50-99 \%$, but the permeability coefficient of water and gas increased. Hay et al. [5] studied the role of steel and polyvinyl alcohol (PVA) fibers in concrete and found that $1.65 \%$ volume fraction of composite fibers was beneficial to improve the applicability and durability of concrete structures. Song and Yin [6] studied the mixing of $0.5 \%, 1 \%, 1.5 \%$ steel fibers and $0.1 \%$ carbon fibers and found that the addition of fibers could improve the compressive strength and compressive toughness of concrete. In this study, through the design of steel fiber reinforced concrete (SFRC), polypropylene fiber reinforced concrete (PFRC) and steel-polypropylene hybrid fiber reinforced concrete (SP-HFRC) specimens, the performance optimization effect of hybrid fiber was studied. It was found that the best performance optimization effect was obtained when the content of steel fiber (SF) is $1 \%$, and the content of polypropylene fiber (PF) was $0.1 \%$. This study makes some contributions to the further application of SP-HFRC in practical engineering.

\section{CONCRETE MATERIAL WITH HYBRID FIBERS}

At present, steel fibers (SF) [7], polypropylene fibers (PF) [8], basalt fibers (BF) [9] and carbon fibers (CF) [10] are fibers which are frequently used in concrete. It is found that the addition of fibers can prevent the expansion of cracks in concrete, improve the tensile and bending resistance, and enhance the corrosion resistance of steel bars [11], which has a good development prospect. Hybrid Fiber Reinforced Concrete (HFRC) refers to the concrete which is added with two or more kinds of fibers in concrete to optimize the performance of concrete in many aspects. At present, the mixing of fibers mainly includes the following forms:

(1) the mixing of main fibers and minor fibers;

(2) the mixing of one fiber in different sizes;

(3) the mixing of different kinds of fibers with similar sizes;

(4) the mixing of fibers with different sizes and types.

It is found that the mixing of metal fibers and non-metal fibers plays an excellent role in optimizing the performance of concrete. Therefore, the performance of SP-HFRC was analyzed in this study.

\section{MATERIALS AND METHODS}

\section{Materials}

Cement: 42.5R ordinary Portland cement, Dalian Xiaoyetian Cement Plant.

Coarse aggregate: gravel with particle size between $5 \mathrm{~mm}$ and $20 \mathrm{~mm}$ and $1.3 \%$ mud content.

Fine aggregate: river sand with 2.48 fineness modulus.

Water reducer: polycarboxylic acid water reducing agent, Beijing Muhu Admixture Co., Ltd.

Water: ordinary tap water.

SF: Hengshui Guangjun Rubber and Plastic Products Co., Ltd. (Figure 1), and its performance indicators are shown in Table 1. 
PF: Wanfeng Building Materials Chemical Co., Ltd. (Figure 2), and its performance indicators is shown in Table 1.

Tab. 1 - Performance indicators of fibers

\begin{tabular}{|c|c|c|}
\hline & SF & PF \\
\hline Length $/ \mathrm{mm}$ & 35 & 12 \\
\hline Diameter $/ \mathrm{mm}$ & 0.8 & 0.035 \\
\hline Density $/\left(\mathrm{g} / \mathrm{m}^{3}\right)$ & 7.8 & 0.91 \\
\hline Tensile strength/MPa & $\geq 800$ & $\geq 350$ \\
\hline Elasticity modulus/GPa & 210 & 3.5 \\
\hline
\end{tabular}

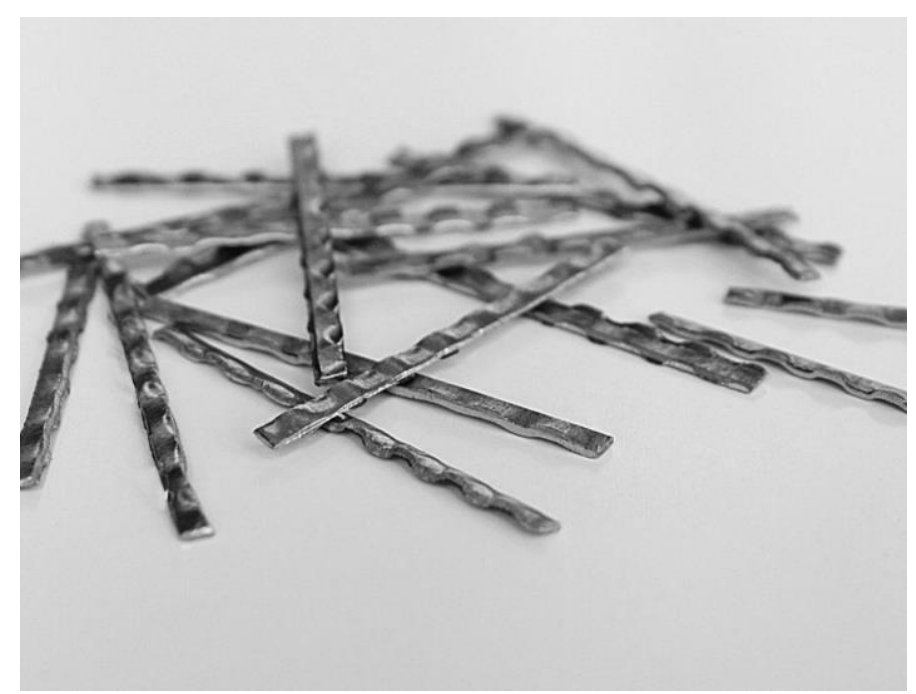

Fig. 1 - Steel fibers

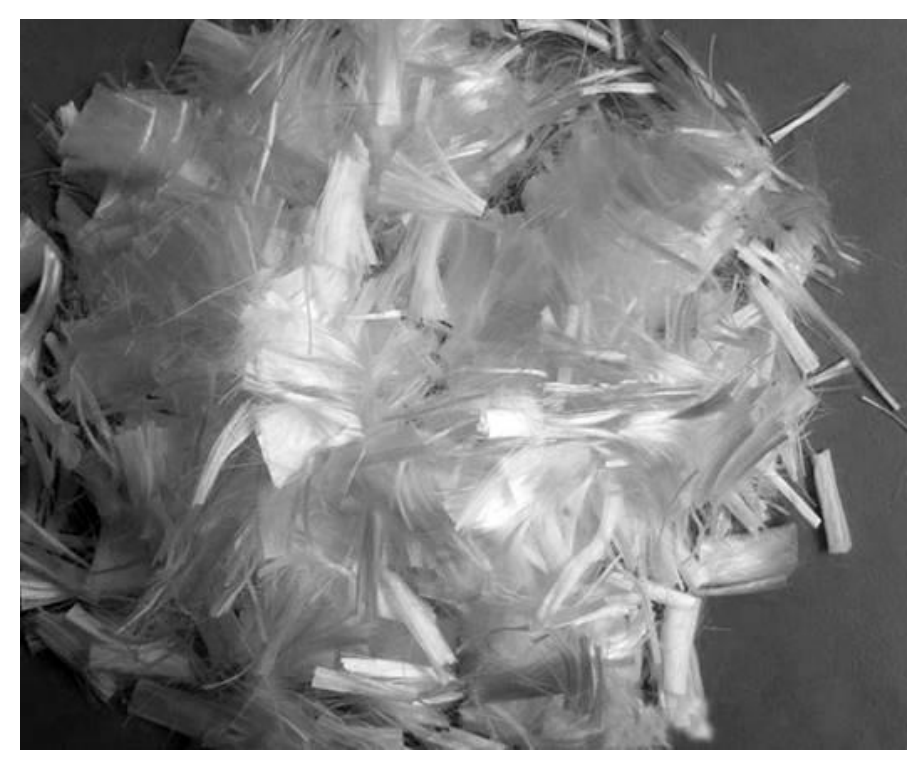

Fig. 2 - Polypropylene fibers 


\section{Preparation of specimen}

The proportion of cement, coarse aggregate, water and water reducing agent of the concrete was $1: 2.2: 1.8: 0.012$. The amount of cement in $1 \mathrm{~m}^{3}$ concrete was $450 \mathrm{~kg} / \mathrm{m}^{3}$. Fiber content of different specimens is shown in Table 2. PC is plain concrete, SF5 means that the volume of SF in concrete is $0.5 \%, \mathrm{PF} 1$ means that the volume of $\mathrm{PF}$ in concrete is $0.1 \%, \mathrm{~S} 10 \mathrm{P} 1$ means that the content of SF in concrete is $1 \%$ and the content of PF is $0.1 \%$, and so on.

Mixing was done by a forced mixer. Firstly, the coarse aggregate was mixed. During mixing, the fibers were evenly added. Sixty seconds later, cement was added, followed by water reducer and water. The test specimen is shown in Figure 3.

Tab. 2 - Experimental groups

\begin{tabular}{|c|c|c|}
\hline Specimen number & SF volume fraction/\% & PF volume fraction/\% \\
\hline PC & 0 & 0 \\
\hline SF5 & 0.5 & 0 \\
\hline SF10 & 1 & 0 \\
\hline SF15 & 1.5 & 0.1 \\
\hline PF1 & 0 & 0.2 \\
\hline PF2 & 0 & 0.3 \\
\hline PF3 & 0 & 0.1 \\
\hline S10P1 & 1 & 0.2 \\
\hline S10P2 & 1 & 0.3 \\
\hline S10P3 & 1 & \\
\hline
\end{tabular}

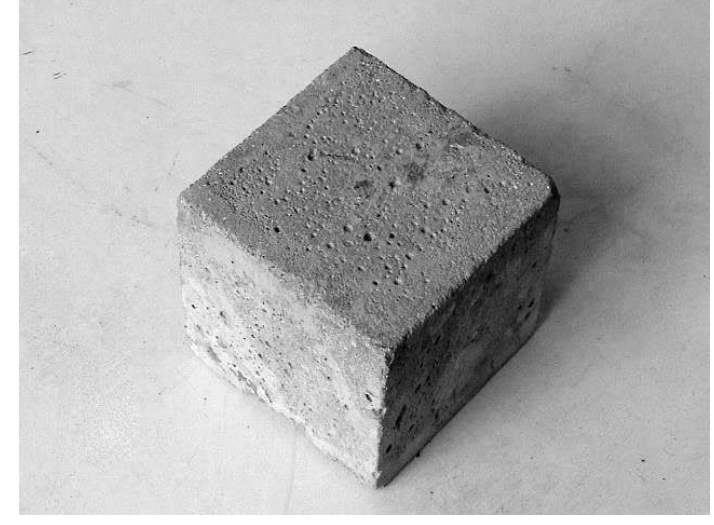

Fig. 3 - The test specimen of concrete

\section{Experimental methods}

(1) Slump test: To ensure that the slump cylinder (Figure 4) was horizontally fixed, the concrete was evenly placed into the cylinder in three layers. After clearing the concrete on the bottom plate of the cylinder, the cylinder was lifted vertically and smoothly between 5 and $10 \mathrm{~s}$. The whole experiment process was controlled within $150 \mathrm{~s}$. The height difference between the height of the 
cylinder and the highest point of the slump concrete was measured, which was regarded the slump value of the concrete.

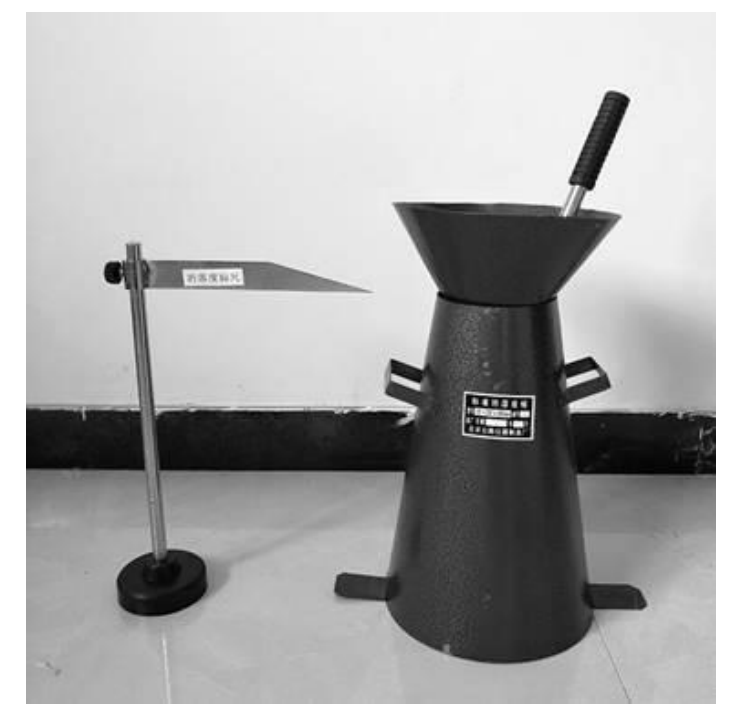

Fig. 4 - Slump cylinder

(2) Compression test: A specimen in a size of $150 \mathrm{~mm} \times 150 \mathrm{~mm} \times 150 \mathrm{~mm} \times 150 \mathrm{~mm}$ was loaded by JES-2000A pressure tester (Figure 5). The specimen was placed in the middle of the lower pressure plate, and the bearing surface was perpendicular to the top surface to ensure the balanced contact between the upper pressure plate and specimen. The loading speed was between $11.25 \mathrm{kN} / \mathrm{s}$ and $18 \mathrm{kN} / \mathrm{s}$. The loading continued until the specimen was destroyed. Compressive strength $f=\frac{F}{A}$, where $F$ stands for the failure load of the specimen and $A$ stands for the bearing area of the specimen.

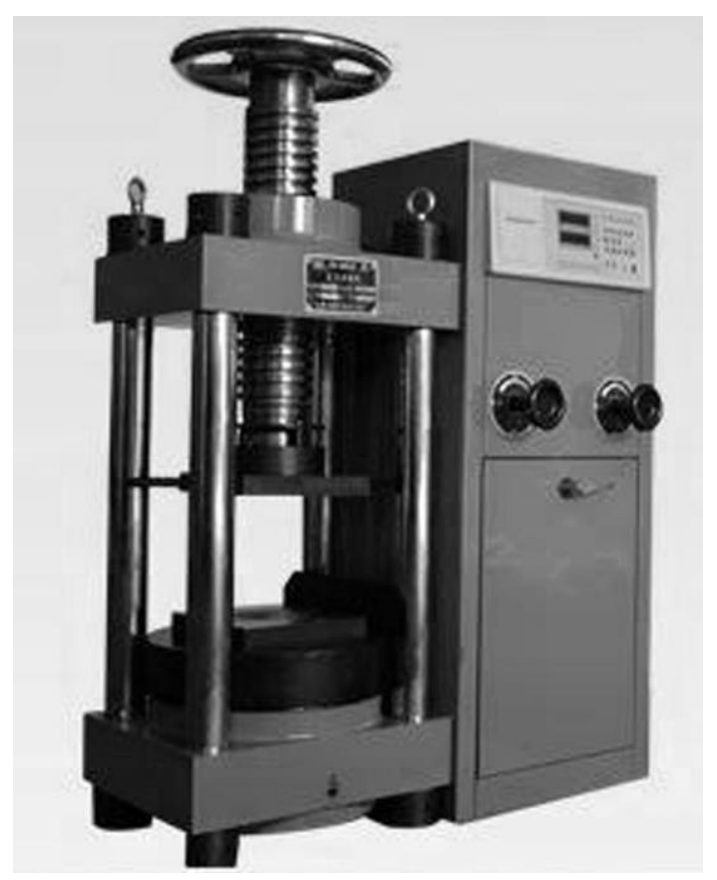

Fig. 5- JES-2000A Pressure Testing Machine 
(3) Tensile test: A specimen in a size of $150 \mathrm{~mm} \times 150 \mathrm{~mm} \times 150 \mathrm{~mm} \times 150 \mathrm{~mm}$ was loaded by WE-600C hydraulic universal testing machine (Figure 6). Firstly, the center line was drawn on the specimen, and then the cushion block, cushion strip and specimen were placed in turn. All the centers were aligned with the center line of the pressure plate of the testing machine, and the loading speed was between $0.05 \mathrm{Mpa} / \mathrm{s}$ and $0.08 \mathrm{Mpa} / \mathrm{s}$. The loading continued until the specimen was destroyed. Tensile strength $f=0.637 \frac{F}{A}$, where $F$ stands for the failure load of the specimen and $A$ stands for the split area of the specimen.

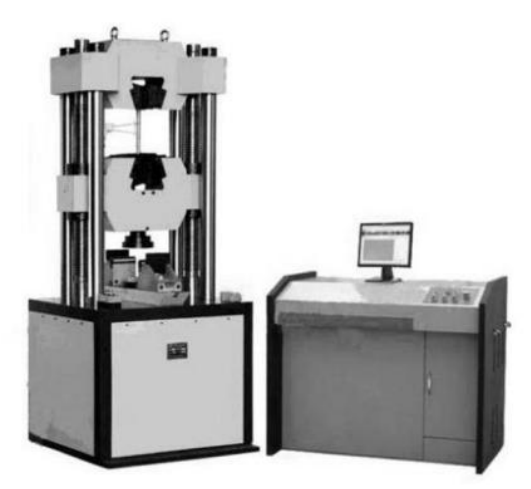

Fig. 6 - WE-600C Hydraulic Universal Testing Machine

\section{RESULTS}

\section{Slump}

The slump values of different specimens are shown in Figure 7.

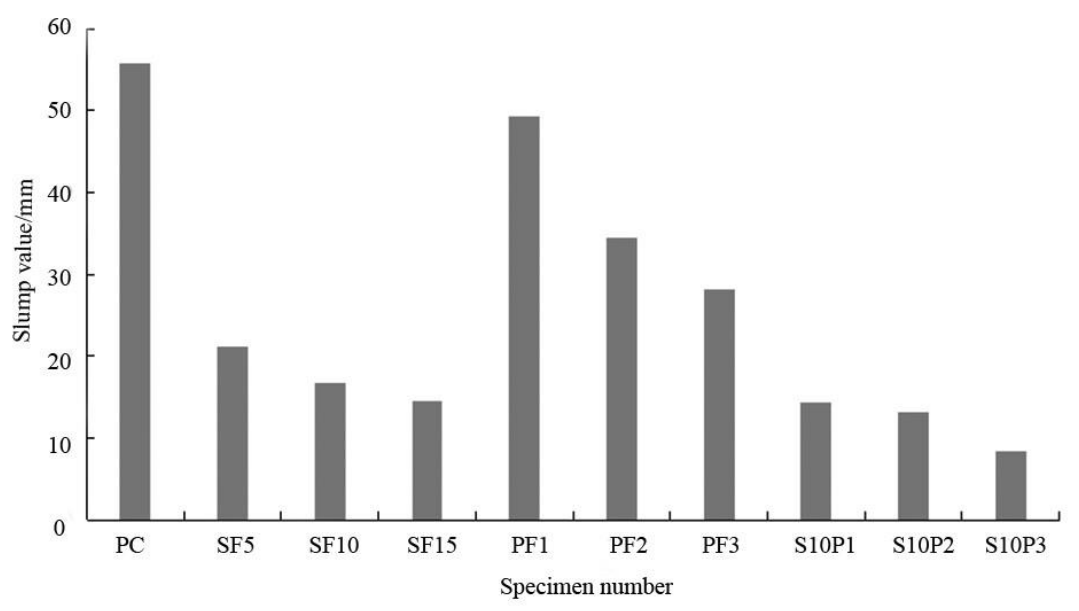

Fig. 7- Slump values of different specimens

It was found from Figure 7 that the type and content of fibers had a significant impact on slump. The slump value of PC was the highest. In SFRC and PFRC, with the increase of fiber content, the slump decreased gradually; the impact of SF on slump was greater. In HFRC, the increase of fiber content also reduced the slump. High slump indicates that concrete has good fluidity and cohesion. Considering slump, the fiber content in HFRC should be as low as possible. 


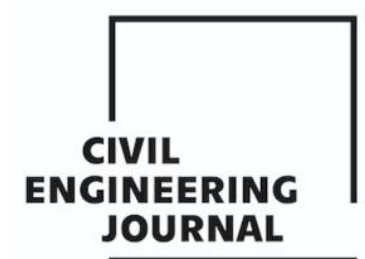

\section{Compressive strength}

The compressive strength of different specimens is shown in Figure 8.

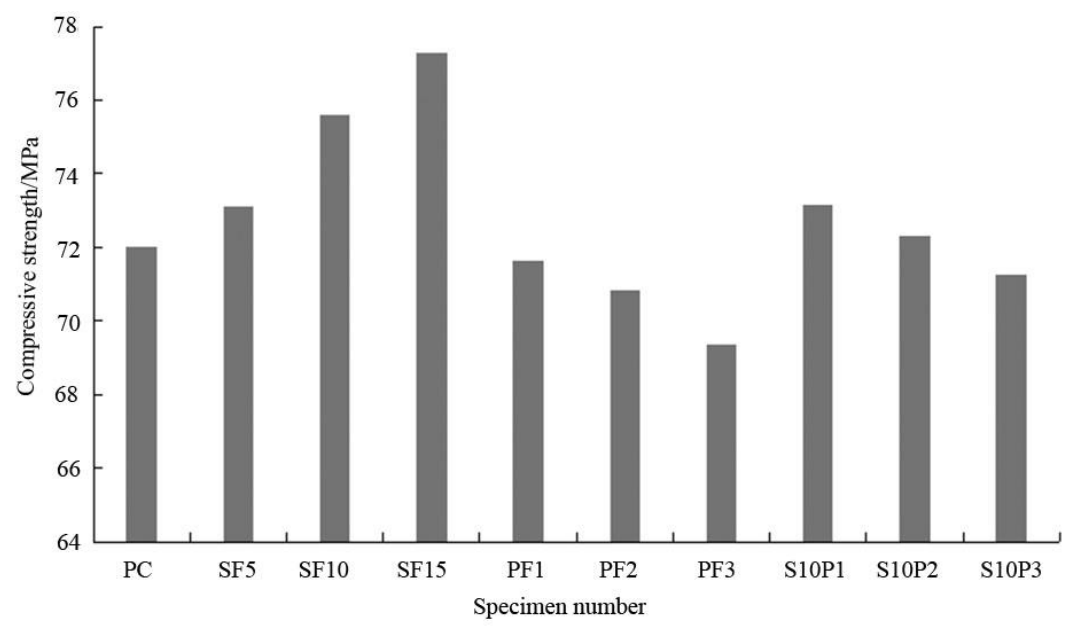

Fig. 8-Compressive strength of different specimens

It was found from Figure 8 that the compressive strength of SFRC was higher than that PC, while PFRC was slightly lower than PC. When the content of SF content was $1.5 \%$, the compressive strength of concrete reached 77.27 MPa, the highest, $7.3 \%$ higher than $\mathrm{PC}$. When the content of PF was $0.3 \%$, the compressive strength of concrete is $69.36 \%, 3.7 \%$ lower than PC. The change of compressive strength of HFRC was between SFRC and PFRC; HFRC had slight improvement compared to PC. When the content of SF was $1 \%$ and the content of PF was $0.1 \%$, the compressive strength of concrete reached 73.16 MPa, the highest, 1.6\% higher than PC.

\section{Tensile strength}

The tensile strength of different specimens is shown in Figure 9.

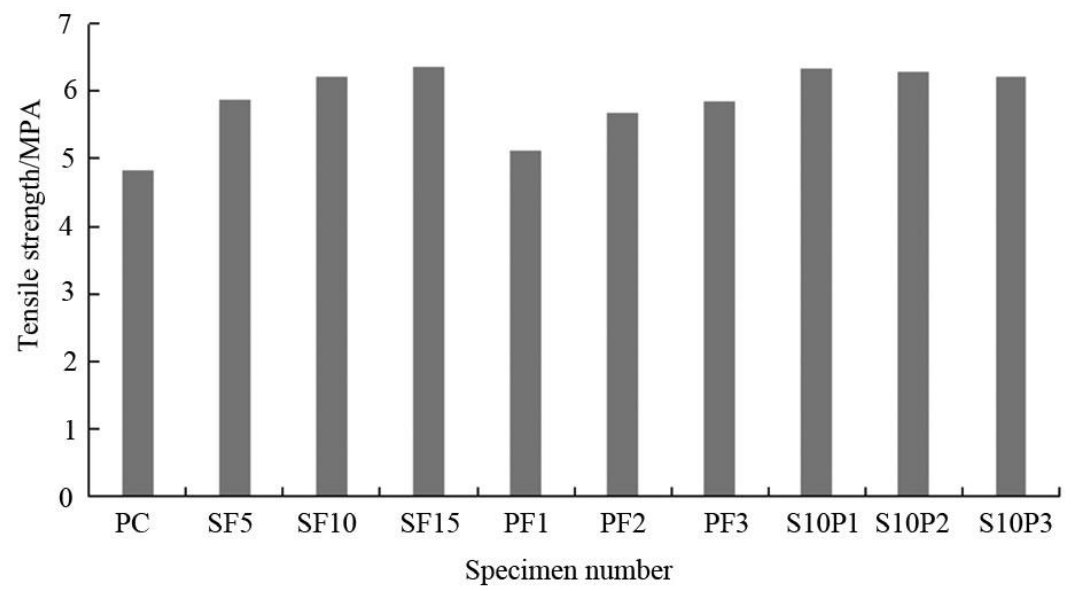

Fig. 9 - Tensile strength of different specimens

It was found from Figure 9 that the addition of SF could significantly enhance the tensile strength of concrete. When the content of SF was $1.5 \%$, the tensile strength of SFRC was $31.68 \%$ higher than that of PC. When the content of PF was $0.3 \%$, the tensile strength of PFRC was $20.91 \%$ 
higher than that of PC. When the content of SF was $1 \%$ and the content of PF was $0.1 \%$, the tensile strength of HFRC was higher than that of single-fiber concrete, $1.9 \%$ higher than SF10 and $23.6 \%$ higher than PF1.

\section{SEISMIC PERFORMANCE}

It was found from the comprehensive experimental results that when the content of SF was $1 \%$ and the content of PF was $0.1 \%$, the performance optimization effect of the SP-HFRC specimen was obvious. To analyze the seismic performance of the specimen, concrete columns were prepared using PC and concrete containing $1 \%$ SF and $0.1 \%$ PF. The cross-section size of the column was $250 \times 250 \mathrm{~mm}$. The concrete base was $400 \times 400 \times 900 \mathrm{~mm}$. The longitudinal steel bar was HRB400. The stirrup was HPB300. The parameters of steel bars are shown in Table 3 . The reinforcement ratio was $1.62 \%$. The stirrup ratio was $0.62 \%$, and the ratio of axial compression stress to strength was 0.35 . The structure of the test specimen is shown in Figure 10.

Tab. 3 - Parameters of steel bars

\begin{tabular}{|c|c|c|}
\hline & HRB400 & HPB300 \\
\hline Diameter/mm & 14 & 8 \\
\hline Yield strength/MPa & 552.98 & 330.76 \\
\hline Ultimate strength/MPa & 670.29 & 437.15 \\
\hline
\end{tabular}

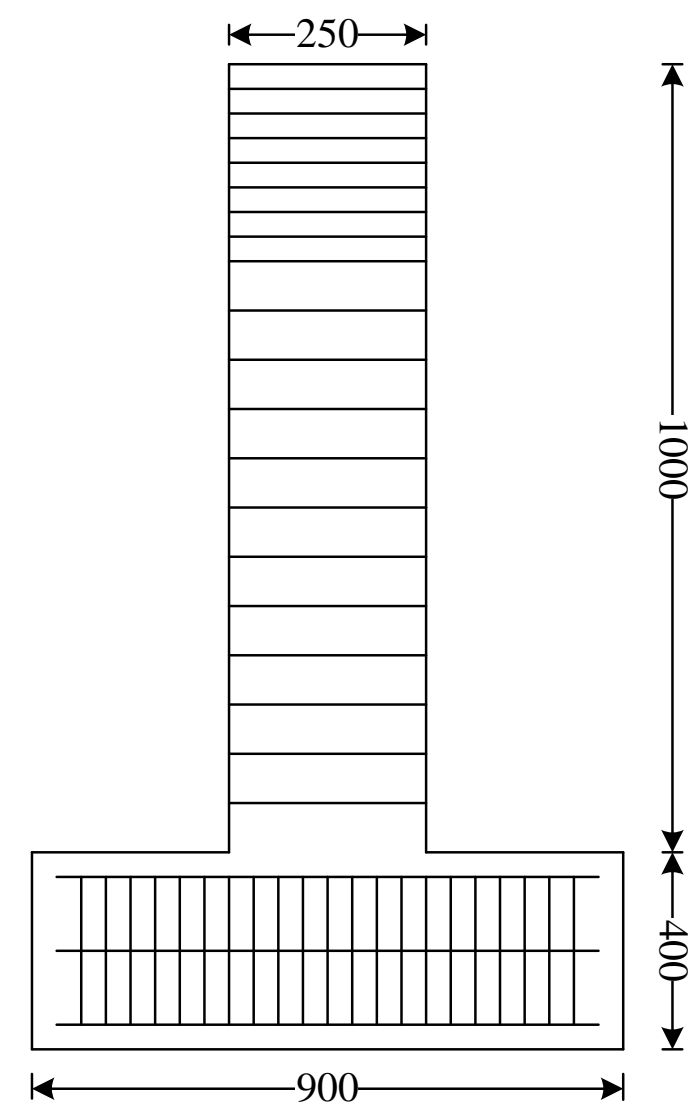

Fig. 10 - The structure of the test specimen 
The seismic performance of the test specimen was tested by the pseudo static test. The axial load was loaded using an oil jack. The repeated load was applied at the beam end using a hydraulic servo actuator at a loading rate of $0.4 \mathrm{~mm} / \mathrm{s}$, and the loading continued until the load of the beam end significantly reduced. The layout of measuring points is shown in Figure 11 and 12.

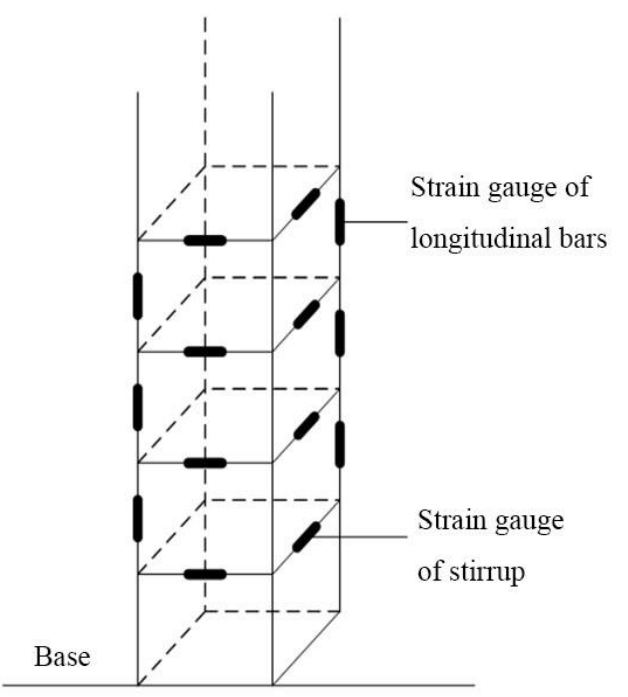

Fig. 11 - The layout of strain gauges

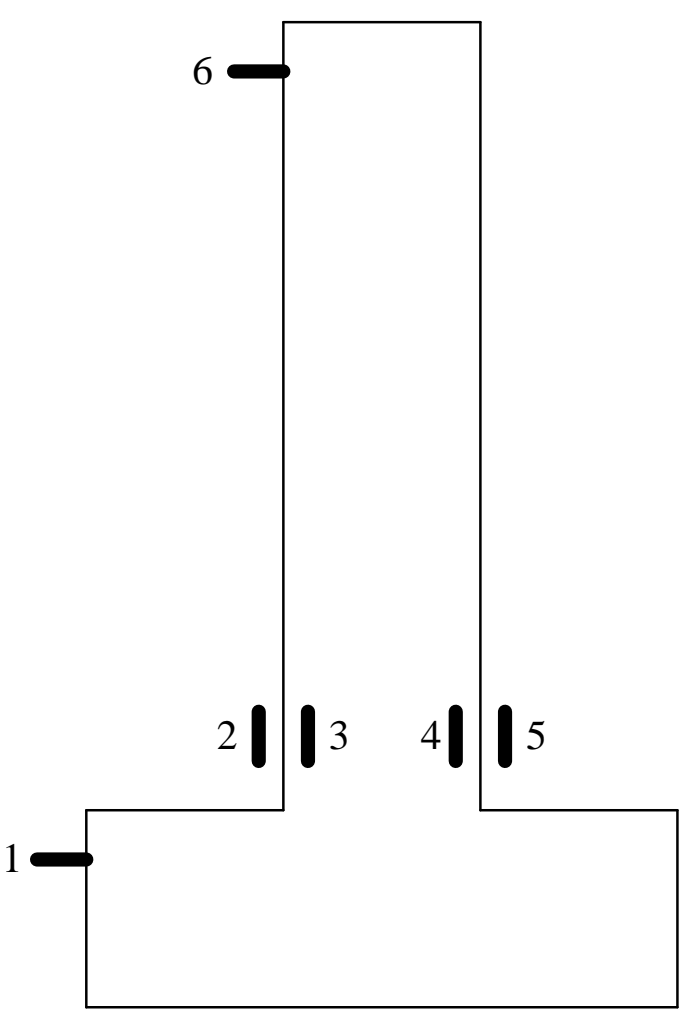

Fig. 12 - The layout of displacement meters

The loading of the two test specimens is shown in Table 4. 


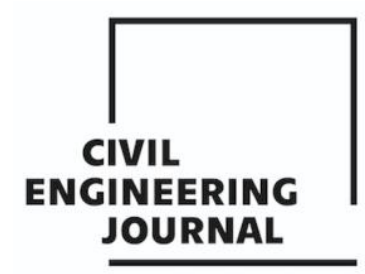

Article no. 37

THE CIVIL ENGINEERING JOURNAL 2-2021

Tab. 4 - Comparison of load

\begin{tabular}{|c|c|c|}
\hline & PC & SP-HFRC \\
\hline Cracking load/kN & 19.87 & 24.78 \\
\hline Yield load/kN & 39.68 & 45.32 \\
\hline Ultimate load/kN & 46.76 & 48.69 \\
\hline Final load/kN & 39.87 & 42.36 \\
\hline
\end{tabular}

It was seen from Table 4 that the loads of the SP-HFRC specimen were significantly larger than those of the PC specimen, indicating that the strength of the SP-HFRC column had more significant improvement than the PC column; the final load of the SP-HFRC specimen was $6.25 \%$ larger than that of the PC specimen. It was found that the addition of fibers was beneficial to the seismic performance of the structure.

The energy consumption of the test specimens was compared, and the results are shown in Figure 13.

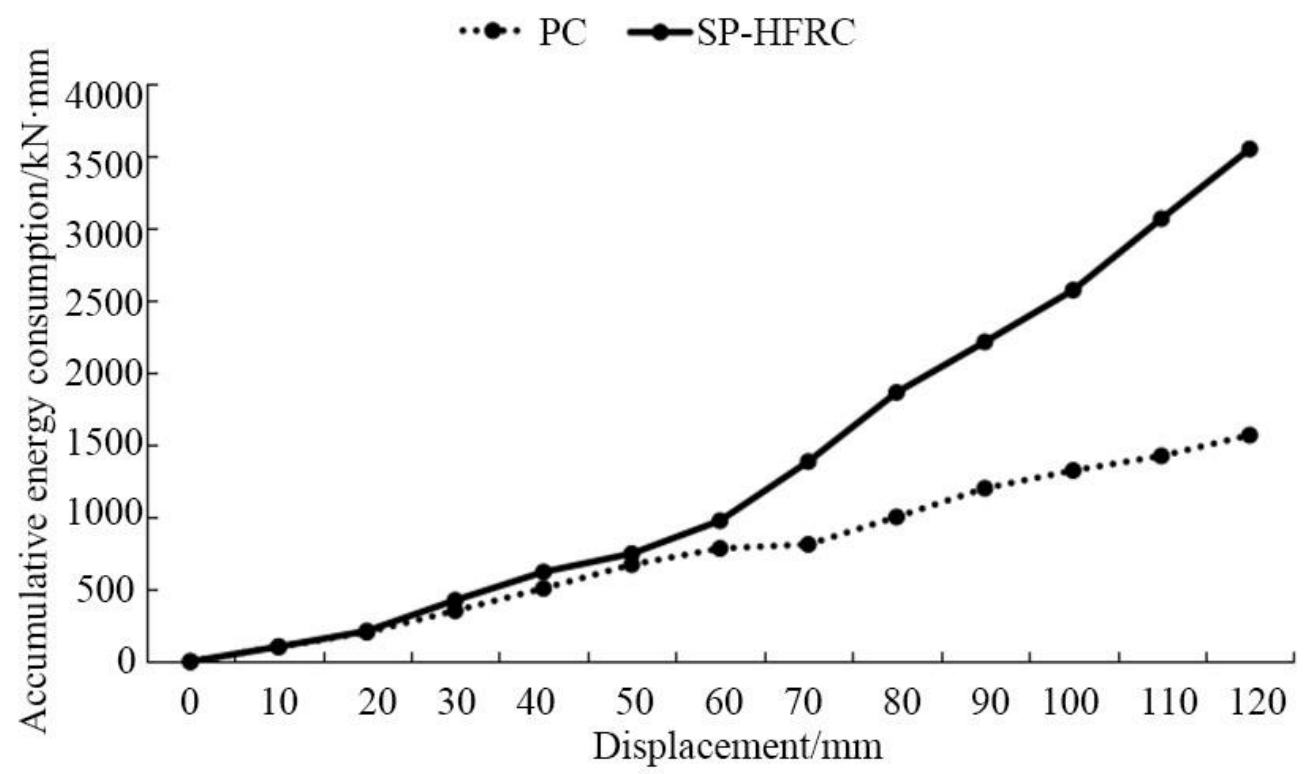

Fig. 13 - Comparison of energy consumption

It was found that the energy consumption of the two test specimens was similar under small displacements, but the difference became larger and the energy consumption of the SP-HFRC specimen was significantly larger with the increase of the displacement. It demonstrated that the addition of fibers significantly improved the energy consumption ability of the structure. Taking 120 $\mathrm{mm}$ displacement as an example, the energy consumption of the SP-HFRC specimen was $126 \%$ higher than that of the PC specimen.

\section{DISCUSSION}

Concrete is one of the most important building materials, and the research on performance optimization of concrete plays an important role in social and economic development. It is found that fibers plays an important role in optimizing the performance of concrete and they can improve the 


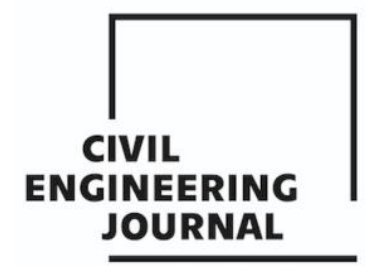

Article no. 37

THE CIVIL ENGINEERING JOURNAL 2-2021

compressive strength of concrete [12], restrain cracks, delay corrosion [13], and enhance the bonding strength between concrete and steel bars [14]. HFRC composed of two or more mixed fibers can give full play to the advantages of multiple fibers and has high practical application values in building structure.

This study mainly focused on the optimization effect of SF and PF on concrete performance, designed SFRC, PFRC and SP-HFRC specimens, and tested their performance. Firstly, it was found from the slump measurement results (Figure 7) that the addition of fibers reduced the slump, and the higher the content of fibers, the lower the slump. It might be because that the addition of fibers adsorbed more moisture, which reduced the water content in concrete, and moreover SF and PF also increased the viscosity of concrete, resulting in the decline of slump and the decrease of concrete fluidity. The experimental results of compressive strength (Figure 8 ) demonstrated that the addition of SF increased the compressive strength of specimens, and the addition of PF decreased the compressive strength of specimens. In S P-HFRC, the change of compressive strength was between the specimens with single SF and PF. When the content of SF was $1 \%$ and the content of PF was $0.1 \%$, the maximum compressive strength was $73.16 \mathrm{MPa}$, which was $1.6 \%$ higher than that of PC. It was found from Figure 8 that the tensile strength of SFRC was significantly higher than that of $\mathrm{PC}$, and the higher the content of SF, the larger the improvement. When the content of SF was $1.5 \%$, the tensile strength of SP-HFRC was $31.68 \%$ higher than that of PC. The tensile strength of SP-HFRC was also higher than that of PC and higher than that of the concrete added with the same content of single fiber. The comparison of the load and energy consumption between the two concrete columns in the analysis of the seismic performance of the test specimens showed that the addition of mixed fibers was effective in enhancing the seismic performance of the building structure. Firstly, fibers could improve the strength of the concrete column. It was seen from Table 4 that the SP-HFRC specimen had high load, indicating that it had high strength. Then, in the perspective of energy consumption, with the increase of the displacement, the accumulative energy consumption of the SP-HFRC specimen was significantly larger than that of PC, showing that the SP-HFRC specimen had better energy consumption ability.

It was concluded from the experimental results that the incorporation of fibers could reduce the collapse degree of concrete, was not conducive to the fluidity of concrete, and had an inconspicuous optimization effect on compressive strength, but it had a good strengthening effect on the tensile strength. When the content of SF was $1 \%$ and the content of PF was $0.1 \%$, the concrete had improved compressive and tensile strength and good strength and energy consumption ability.

Although some achievements on research of SP-HFRC have been obtained in this study, there are still many shortcomings, which need to be improved in further work.

(1) This study only considers the content of fiber, but does not consider the influence of fiber length, shape, etc.

(2) The properties of concrete such as high temperature resistance, low temperature resistance, seismic resistance and impermeability need further study.

(3) Study on the blending of more than two kinds of fibers is needed.

(4) The influence of additives such as water reducing agent was not taken into account.

\section{CONCLUSION}

In this study, the mechanical property of SP-HFRC in building structure was analyzed through experimental design, and the properties of SFRC, PFRC, and SP-HFRC with different content of fibers were compared. It was found that: 


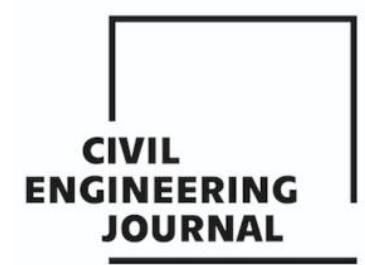

(1) the increase of fibers reduced the slump of the concrete;

(2) the increase of fibers improved the compressive and tensile strength of the concrete;

(3) compared with SFRC and PFRC, SP-HFRC presented better mechanical properties; when the content of SF and PF was $1 \%$ and $0.1 \%$ respectively, the performance of SP-HFRC was optimal.

(4) compared with the PC column, the SP-HFRC column had better strength and energy consumption ability, i.e., better seismic performance.

\section{REFERENCES}

[1] Mazzoli A., Monosi S., Plescia E.S., 2015. Evaluation of the early-age-shrinkage of Fiber Reinforced Concrete (FRC) using image analysis methods. Construction \& Building Materials, vol. 101: 596-601.

[2] Köroğlu M.A., Özdöner N., 2016. Behavioural study of steel fiber and polypropylene fibre reinforced concrete. Key Engineering Materials, vol. 708: 59-63.

[3] Yang J.M., Yoo D.Y., Kim Y.C., Yoon Y.S., 2017. Mechanical properties of steam cured highstrength steel fiber-reinforced concrete with high-volume blast furnace slag. International Journal of Concrete Structures and Materials, vol. 11: 391-401.

[4] Sadiqul Islam G.M., Gupta S.D., 2016. Evaluating plastic shrinkage and permeability of polypropylene fiber reinforced concrete. International Journal of Sustainable Built Environment, S2212609015300789.

[5] Hay R., Ostertag C., 2014. Development and application of high performance green hybrid fiberreinforced concrete (HP-G-HyFRC) for sustainable and energy-efficient buildings. Key Engineering Materials, vol. 629-630: 299-305.

[6] Song W., Yin J., 2016. Hybrid effect evaluation of steel fiber and carbon fiber on the performance of the fiber reinforced concrete. Materials, vol. 9: 704-.

[7] Soufeiani L., Raman S.N., Jumaat M.Z.B., Alengaram U.J., Ghadyani G., Mendis P., 2016. Influences of the volume fraction and shape of steel fibers on fiber-reinforced concrete subjected to dynamic loading - A review. Engineering Structures, vol. 124: 405-417.

[8] Huang L., Xu L., Chi Y., Xu H., 2015. Experimental investigation on the seismic performance of steel-polypropylene hybrid fiber reinforced concrete columns. Construction and Building Materials, vol. 87: 16-27.

[9] Kizilkanat A.B., Kabay N., Akyüncü V., Chowdhury S., Akca A.H., 2015. Mechanical properties and fracture behavior of basalt and glass fiber reinforced concrete: An experimental study. Construction \& Building Materials, vol. 100: 218-224.

[10] Dundar C., Erturkmen D., Tokgoz S., 2015. Studies on carbon fiber polymer confined slender plain and steel fiber reinforced concrete columns. Engineering Structures, vol. 102: 31-39.

[11] Blunt J., Jen G., Ostertag C.P., 2015. Enhancing corrosion resistance of reinforced concrete structures with hybrid fiber reinforced concrete. Corrosion Science, vol. 92: 182-191.

[12] Düğenci O., Haktanir T., Altun F., 2015. Experimental research for the effect of high temperature on the mechanical properties of steel fiber-reinforced concrete. Construction and Building Materials, vol. 75: 8288.

[13] Nguyen W., Duncan J.F., Monteiro P.J.M., Ostertag C.P., 2016. Multi-scale characterization of corrosion initiation of preloaded hybrid fiber-reinforced concrete composites. Key Engineering Materials, vol. 711: 195-202.

[14] Garcia-Taengua E., Martí-Vargas J.R., Serna P., 2016. Bond of reinforcing bars to steel fiber reinforced concrete. Construction and Building Materials, vol. 105: 275-284. 